\title{
PEDAGOGIAS DA POLARIZAÇÃO NO FACEBOOK: REDES SOCIAIS ONLINE E URGÊNCIA OPINATIVA
}

\author{
PEDAGOGIES OF POLARIZATION ON FACEBOOK: ONLINE SOCIAL NETWORKS AND URGENCY OF OPINION
}

PEDAGOGÍAS DE POLARIZACIÓN EN FACEBOOK: REDES SOCIALES EN LÍNEA Y URGENCIA DE OPINIÓN

\author{
ZAGO, Luiz Felipe 1 \\ SANTOS, Aloha Boeck Arruda dos²
}

\begin{abstract}
RESUMO
O artigo parte de publicações e comentários de seguidores das páginas oficiais de Danilo Gentili e Gregório Duvivier no Facebook entre os dias 26 de julho e 4 de outubro de 2018 para caracterizar a polarização política nessa rede social. Arregimenta o estatuto pedagógico da mídia para entender regulação dos afetos que acontece nas redes sociais online. Discute, ao fim, a noção de "urgência opinativa" para compreender as disputas sobre o sentido de democracia que aparecem nas publicações e comentários dos seguidores. Essas disputas tratam as opiniões diversas como inimigos a serem exterminados, obliterando a condição democrática pluralista.
\end{abstract}

Palavras-chave: Redes sociais online. Democracia. Pedagogias culturais. Afetos.

\section{ABSTRACT}

The article starts analyzing posts and comments made by followers of Danilo Gentili and Gregório Duvivier official Facebook pages between July 26th and October 4th, 2018 to demonstrate the political division on this social network. It uses social media pedagogical status to understand the regulation of the online social network affections. It proposes the notion of "urgency of opinion" to comprehend the disputes on the senses of democracy that appear on social networks. These disputes consider diverse opinions as enemies to be exterminated, destroying the mixed democratic condition.

Keywords: Online social network. Democracy. Cultural pedagogies. Affections.

\section{RESUMEN}

El artículo parte desde publicaciones y comentarios de seguidores de las páginas oficiales en Facebook de Danilo Gentili y Gregório Duvivier entre el 26 de julio del 2018 y el 4 de octubre del 2018 para demostrar la polarización política en esta red social. Comienza a partir del estado pedagógico de los medios de comunicación para comprender la regulación del afecto que ocurre en las redes sociales. Se propone el sentido de "urgencia de opinión" para comprender las disputas sobre el significado de la democracia que aparecen en las publicaciones y comentarios de los seguidores. Estas disputas tratan opiniones diversas como enemigos a ser exterminados, destruyendo la condición democrática pluralista.

Palabras clave: Redes sociales en línea. Democracia. Pedagogías culturales. Efectos.

\footnotetext{
${ }^{1}$ Universidade Luterana do Brasil - ULBRA - Brasil.

2 Universidade Luterana do Brasil - ULBRA - Brasil.
} 


\section{INTRODUÇÃO}

Como a urgência em publicizar opiniões se manifestou no uso de uma rede social na internet em um período conturbado, como foi a campanha eleitoral no Brasil em 2018? Essa é a pergunta que estimulou a realização deste artigo, produto parcial de uma Dissertação de Mestrado (SANTOS, 2019), cujas respostas serão esboçadas a seguir.

O primeiro turno das eleições contava com treze candidatos ao cargo de chefe do executivo no país, mas a disputa polarizou-se entre os candidatos Jair Bolsonaro e Fernando Haddad. A conformação de um cenário de acirrada polarização política, em especial nas redes sociais da internet, se acelerou partir das publicações das primeiras pesquisas de intenção de voto. Nesse contexto, os comportamentos de usuários dessas redes permitem análises sobre o quanto passou a ser importante a publicação das opiniões pessoais - sobretudo quando o assunto se tornou posicionamentos políticos (D'ANDRÉA, 2016). Ressignificadas pelas tecnologias da comunicação, os atos de curtir, compartilhar e comentar tornaram-se atitudes cuidadosamente avaliadas por usuários das redes (RECUERO, 2014). Curtir, compartilhar, e comentar o tema da política brasileira naquela plataforma tornaram-se práticas sociais que hoje integram uma rede de interação cotidiana e que exprimem disputas pelo sentido de democracia, conforme argumentaremos.

Assim, o presente artigo apresenta publicações e comentários de seguidores das páginas oficiais de Danilo Gentili ${ }^{3}$ e Gregório Duvivier ${ }^{4}$ no Facebook para caracterizar como os usos de redes sociais da internet atuam na produção de um contexto polarizado no dado período. À pergunta norteadora, exposta no primeiro parágrafo, articulamos o objetivo do artigo: sustentar, ao fim, a ideia de "urgência opinativa" como uma prática singular da polarização política do Brasil contemporâneo, principalmente nas redes sociais online.

O recorte do material empírico ${ }^{5}$ selecionou quatro publicações que estimularam maior engajamento dos seguidores das páginas de Danilo Gentili e Gregório Duvivier (somados os números de curtidas, compartilhamentos e comentários): duas publicações durante as cinco semanas de duração da campanha eleitoral do primeiro turno (quando, então, os candidatos poderiam ter suas propagandas em todas as mídias), realizada entre 31 de agosto e 4 de outubro de 2018, e outras duas publicações das cinco semanas anteriores ao início do primeiro turno, entre 26 de julho a 30 de agosto de 2018. Ao analisar publicações e comentários dessas figuras públicas em redes sociais na internet nesse recorte temporal dependemos, de certo modo, da "plataformização das controvérsias": "as plataformas são cada vez mais não apenas os ambientes com as quais as controvérsias se desenrolam, mas muitas vezes o fator desencadeador de novas disputas e conflitos", na medida em que a definição e relevância de engajamentos depende do funcionamento das "tecnopolíticas das

\footnotetext{
3 Ator, comediante e apresentador. Já trabalhou em veículos de comunicação como a Rede Bandeirantes. Em 2020 era apresentador do programa "The Noite", no canal aberto SBT.

${ }^{4}$ Ator, comediante e escritor. Roteirista e ator do grupo Porta dos Fundos. Em 2020 era apresentador do programa "Greg News", no canal pago HBO, e colunista do jornal Folha de São Paulo.

${ }^{5}$ A pesquisa original adotou o mesmo recorte temporal; entretanto, foram selecionadas para análise as dez publicações (cinco de cada página) e dez de seus comentários com maior número de engajamento.
} 
plataformas", inarredáveis dos funcionamentos sociotécnicos das tecnologias digitais (D'ANDRÉA, 2018, p. 37).

No que segue, primeiramente apontamos elementos presentes nos cinco comentários mais relevantes vinculados às quatro publicações ${ }^{6}$ que tangenciam elementos vinculados à comunicação, à política e à democracia. Depois da apresentação disso que chamamos de "rastros da polarização política no Facebook", articulamos um quadro teórico marcado pela interdisciplinaridade, que se apoia em autoras/es da Sociologia, Comunicação Social e Ciência Política; entretanto, salientamos que assumimos o conceito de "estatuto pedagógico da mídia", em Rosa Maria Bueno Fischer (1997; 2012), como um vetor de convergência teórica a partir do qual propomos considerações sobre a Educação, em seu sentido ampliado, articulada ao uso de redes sociais na internet e às disputas pelo sentido da democracia no Brasil do tempo presente.

\section{“ENFIANDO IDEOLOGIA NA CABEÇA” - RASTROS DA POLARIZAÇÃO POLÍTICA NO FACEBOOK}

As eleições brasileiras de 2018 mostraram a importância da presença digital dos candidatos e o poder exercido pelas redes sociais na decisão do voto. De acordo com uma pesquisa realizada pela MindMinders, encomendada pela $\mathrm{Nexo}^{7}$, sessenta por cento dos participantes informaram que usavam as redes sociais como fonte de informação durante as eleições, sendo que noventa por cento apontaram o WhatsApp e oitenta e cinco por cento o Facebook como principais redes. Dentre os oitenta e cinco por cento que citaram o Facebook, quarenta e dois por cento costumam publicar ou compartilhar conteúdos políticos. Além disso, foram constantes as informações relacionadas à checagem de fatos, em um combate às fake news.

Gentili sempre se posicionou a favor do impeachment, contra o governo Dilma e, principalmente, contra o que ele considera a esquerda brasileira. Com um talk show noturno e diário no canal aberto SBT, e apresentando-se em seus espetáculos de humor stand-up em todo o Brasil, Danilo tem treze milhões de curtidas $^{8}$ em sua página no Facebook. Já Duvivier - que, além de participar do grupo humorístico Porta dos Fundos ${ }^{9}$, também conta com um programa no canal pago HBO - sempre se mostrou contrário ao processo do impeachment de Dilma e se declara de esquerda. Seu número de seguidores no Facebook é consideravelmente menor, com um milhão de curtidas ${ }^{10}$.

\footnotetext{
${ }^{6}$ Estamos cientes de que este tipo de critério metodológico nos faz reféns dos algoritmos (ARAÚJO, 2018) e que há críticas importantes, a serem ainda incorporadas, no que tange ao "engajamento" (GROHMANN, 2018). Entendemos, porém, que a norma algorítmica das redes sociais na internet abrange discussão técnica e teórica que escapa, em parte, do escopo deste artigo.

7 Disponível em https://www.nexojornal.com.br/grafico/2018/10/02/Como-informações-políticas-circulam-noWhatsApp-segundo-esta-pesquisa. Acesso em 12 de setembro de 2019.

8 Número aproximado em acesso no dia 12 de setembro de 2019 . Disponível em https://www.facebook.com/Danilo.Gentili.Oficial/.

${ }^{9}$ Grupo de atrizes e atores de humor inscrito que obteve sucesso no Brasil ao explorar, desde 2012, as possibilidades de produção e compartilhamento de conteúdo por meio da Plataforma YouTube. Ver https://www.youtube.com/user/portadosfundos/about, acesso em 06 de maio de 2020, e http://www.portadosfundos.com.br , acesso em 06 de maio de 2020.

${ }^{10}$ Número aproximado em acesso no dia 12 de setembro de 2019. Disponível em https://www.facebook.com/gregorioduvivier.
} 
Em 26 de agosto de 2018, época de pré-campanha eleitoral, Gentili publicou um vídeo cuja legenda somente diz: "Jornalismo no Brasil é noventa e cinco por cento isso aí" 11 . Com trinta e três mil, quatrocentas e oitenta e três interações, este é o conteúdo mais relevante da página no período. $O$ vídeo mostra o humorista participando do Programa do Raul Gil (SBT) em um quadro que o convidou a "tirar o chapéu" para temas e pessoas. Um dos temas era "Jornalismo Brasileiro", para o qual Danilo não tirou o chapéu. No vídeo, ele faz uma crítica ao dizer que muitos jornalistas fazem propaganda ideológica e "trazem o vitimismo" nas pautas. Em um dos trechos do vídeo ele diz:

\begin{abstract}
"hoje em dia você tem uma classe de jornalistas que vai para universidade, geralmente é na área de humanas, e sofre lavagem cerebral do professor. O cara cresce numa família, o pai dá tudo, a mãe dá tudo, e vai para a universidade. O professor de Humanas faz uma lavagem cerebral no cara e enfia a ideologia dele na cabeça. Quando ele sai da universidade, ele consegue emprego em uma redação de jornal. Em vez de ele fazer jornalismo, ele fica fazendo militância política."
\end{abstract}

No vídeo, Gentili não comenta se o posicionamento dos jornalistas seria de esquerda ou direita. Mais precisamente, é "o professor de Humanas" o responsável pela "lavagem cerebral" nos estudantes que "enfia a ideologia dele na cabeça" - trecho de fala do humorista que dá título a esta seção. A inferência possível é que os professores das Ciências Humanas teriam ideologia de esquerda e os alunos influenciados por isso conseguiriam empregos nas redações com este viés ideológico. Mas nos comentários fica evidente a apropriação feita por seus seguidores e como eles se alinham com a crítica de Gentili. Dos dez comentários mais relevantes da publicação, apenas um não faz elogio direto ao defendido no discurso do humorista - sendo, na verdade, uma manifestação de um seguidor que deseja ir à tevê para "mandar a ex se fuder [sic] em rede nacional".

Figura 1: Os cinco principais comentários da publicação de Danilo Gentili (antes do período eleitoral).

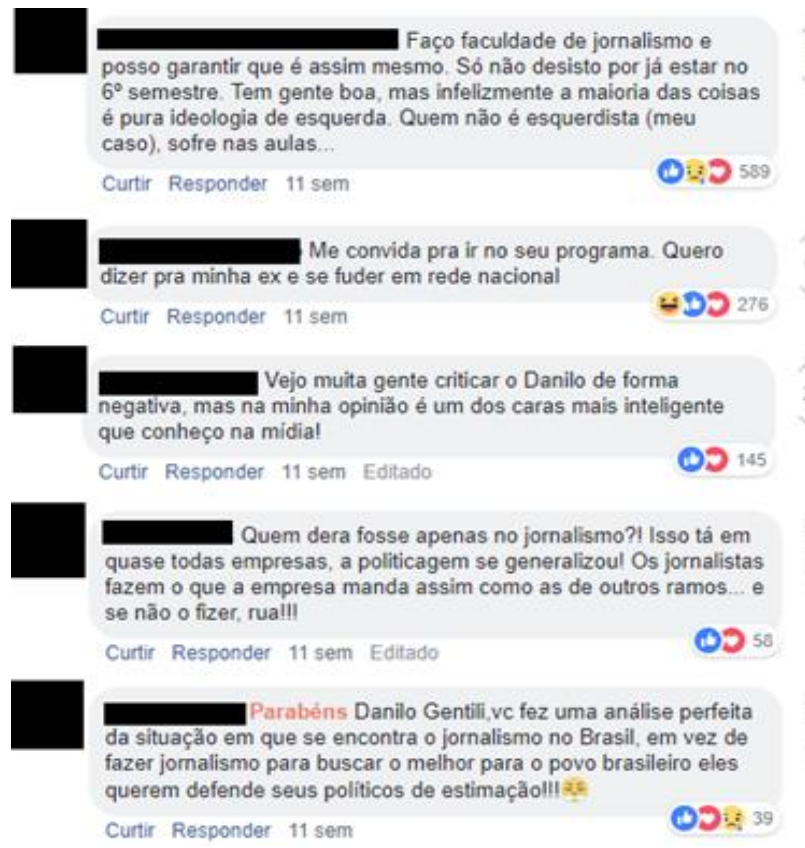

\footnotetext{
${ }^{11}$ Disponível em https://www.facebook.com/Danilo.Gentili.Oficial/videos/542983869464681/. Acesso em 12 de setembro de 2019.
} 
Fonte: Facebook

Concordando com o que diz Gentili, seus seguidores trazem, inclusive, experiências pessoais para sustentação da opinião. Uma das participações vem de um estudante que diz "garantir que é assim mesmo", além de classificar as pessoas de seu curso dizendo que "tem gente boa, mas infelizmente a maioria das coisas é pura ideologia de esquerda", alegando sofrer durante as aulas do curso de graduação por pensar diferentemente. Em outro comentário, um usuário afirma que "a politicagem se generalizou" para muito além do jornalismo, e que se caso um jornalista não cumprir com o que uma empresa manda, o resultado seria a demissão. Outro seguidor argumenta que os jornalistas, "em vez de fazer jornalismo para buscar o melhor para o povo brasileiro", acabam por usar seu ofício para "defende [sic] seus políticos de estimação".

A conexão entre as opiniões colocadas tanto por Gentili quanto pelos comentários contribui para o fortalecimento da ideia que o jornalismo atual é movido e orientado pela ideologia da política de esquerda. Com isso, ao mesmo tempo em que parece apenas falar o que pensa, Gentili também fala o que sua audiência parece gostar de ouvir. O processo opinativo nesse caso é, portanto, de retroalimentação de uma mesma perspectiva, que promove uma crítica em relação à imprensa a partir da visão anti-esquerda. Segundo essa "opinião urgente", os jornalistas não estão prestando um bom serviço, não são bons profissionais, não contribuem para "o melhor do povo brasileiro" por meio de seu ofício, e estariam promovendo "pura ideologia de esquerda" desde a formação universitária dos futuros jornalistas.

Por outro lado, a publicação de maior relevância do período pré-campanha na página de Duvivier traz um vídeo de uma animação para o que ele chama de "Hino da URSAL"12. A música é uma sátira a uma declaração feita pelo deputado federal Cabo Daciolo, então candidato, no primeiro debate dos postulantes à Presidência da República. Durante um questionamento ao candidato Ciro Gomes, Daciolo cita a suposta existência da União das Repúblicas Socialistas da América Latina, URSAL, que seria um projeto da esquerda brasileira. No entanto, esta informação surgiu de uma ironia de que haveria algo semelhante. A suspeita da existência de tal União teria sido propagada a partir de fake news, chegando até o debate presidencial.

Figura 2: Os cinco principais comentários da publicação de Gregório Duvivier (antes do período eleitoral).

\footnotetext{
${ }^{12}$ Disponível em https://www.facebook.com/gregorioduvivier/videos/1906858726042744/ , acesso em 06 de maio de 2020.
} 


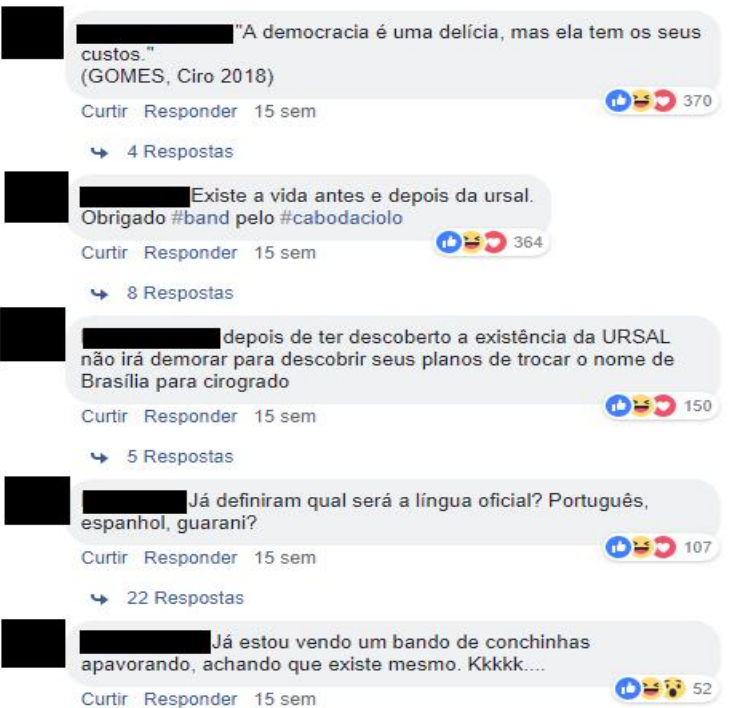

Fonte: Facebook.

Os principais comentários dos seguidores de Duvivier corroboram com o tom irônico da publicação e humorizam sobre a existência da URSAL, aproveitando para criticar a qualidade dos candidatos que participaram do debate. No comentário que diz "Já estou vendo um bando de conchinhas apavorando, achando que existe mesmo. Kkkkk....", vê-se o uso de "conchinhas", que pode ser um erro de digitação do termo "coxinhas", forma como eram chamados os críticos da esquerda no período de manifestações pró-impeachment de Dilma Rousseff. Traços de ironia também aparecem no comentário acerca da suposta língua oficial da URSAL, "Português, espanhol, guarani?", e sobre uma eventual troca de nome da capital federal, Brasília, para "Cirogrado" - em referência a Leningrado, na extinta União Soviética. O comentário mais relevante é "A democracia é uma delícia, mas ela tem os seus custos. (GOMES, Ciro 2018)", no qual o seguidor cita a frase dita pelo candidato Ciro Gomes durante o debate, em resposta ao questionamento sobre a URSAL feita por Daciolo. Neste momento, ao mesmo tempo em que defendia a democracia e, consequentemente, o direito de que assuntos como este fossem discutidos, o candidato dava a entender que também fazia uma crítica ao custo dessa liberdade, que seria responder sobre uma informação equivocada, como era a existência da URSAL.

Durante as cinco semanas anteriores ao período eleitoral, as páginas de Danilo Gentili e Gregório Duvivier atingiram, juntas, trezentas e dezessete mil interações no Facebook entre comentários, compartilhamentos e reações às publicações. Ainda que o volume de interações na página de Danilo seja cinco vezes maior do que a de Gregório, os números são representativos para um contexto geral.

O engajamento dos seguidores nas duas páginas se intensificou durante o período de campanha eleitoral para o primeiro turno, que aconteceu entre os dias 31 de agosto e 4 de outubro de 2018. À época, as páginas tiveram, juntas, um milhão e cem mil de interações com as publicações quase quatro vezes mais que o período anterior. 
O conteúdo com maior engajamento depois de já iniciado o período eleitoral na página de Gentili é um vídeo ${ }^{13}$, do dia 16 de setembro de 2018, intitulado "Modus Operandi da Imprensa Brasileira", que foi publicado junto ao texto "Muitos jornalistas vêem o seu trabalho como uma oportunidade para promover suas próprias noções políticas de estimação, ao invés da responsabilidade de informar o público e permitir que seus leitores e telespectadores decidam por si mesmos. - Thomas Sowell". Ao todo foram trezentas e setenta e nove mil, duzentas e cinco interações com a publicação (entre curtidas, compartilhamentos e comentários), cerca de $42 \%$ de todas as interações do período e quantidade superior a todos os engajamentos das duas páginas no período pré-campanha. Mais uma vez, o humorista investe contra o que considera a forma de atuar do jornalismo brasileiro atual, que na sua opinião estaria ligado à ideologia e partidarismo.

Os cinco comentários mais relevantes desta publicação são estes:

Figura 3: Os cinco principais comentários da publicação de Danilo Gentili (durante o período eleitoral).

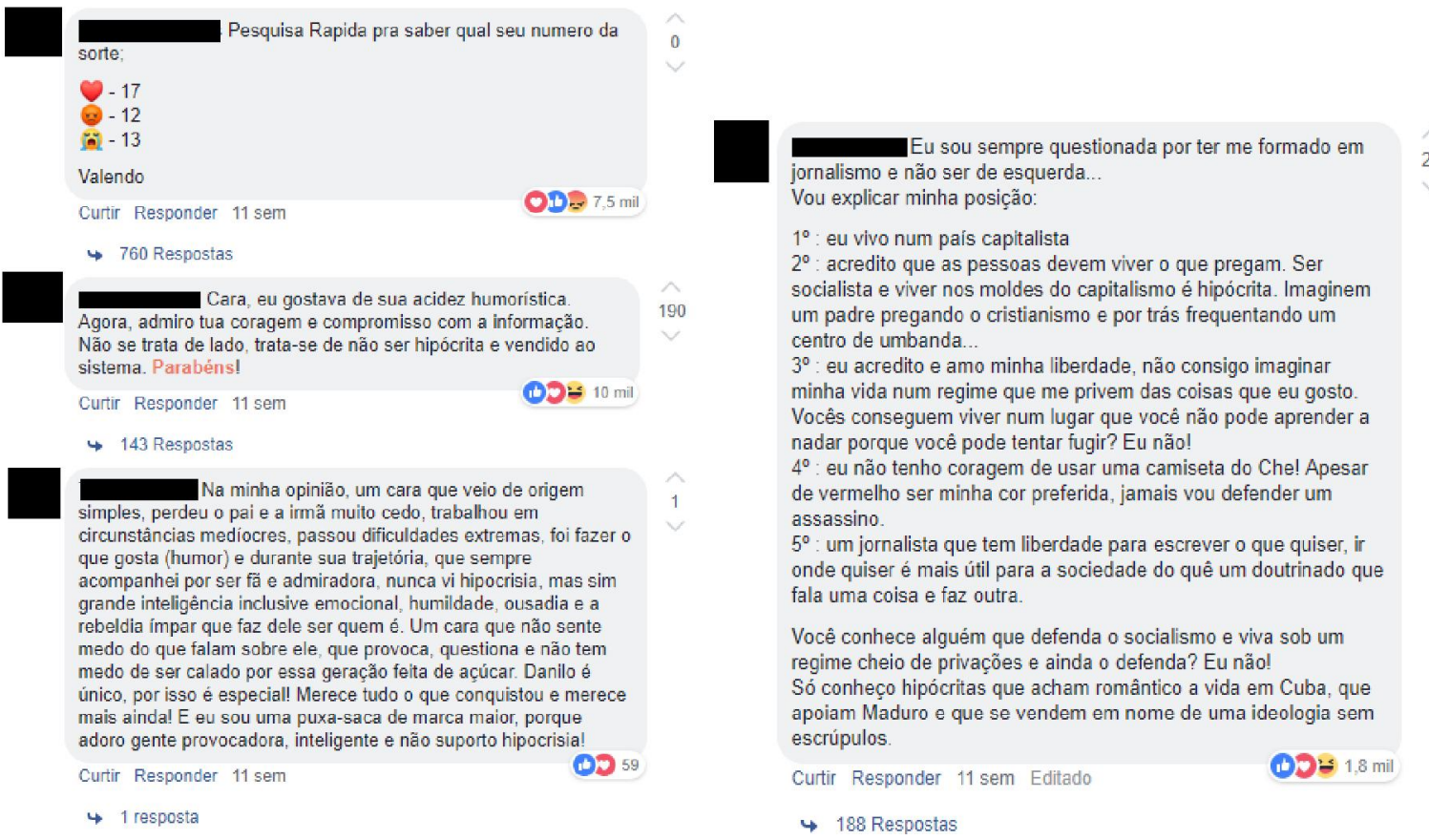

\footnotetext{
${ }^{13}$ Disponível em https://www.facebook.com/Danilo.Gentili.Oficial/videos/266546077306272, acesso em 06 de maio de 2020.
} 


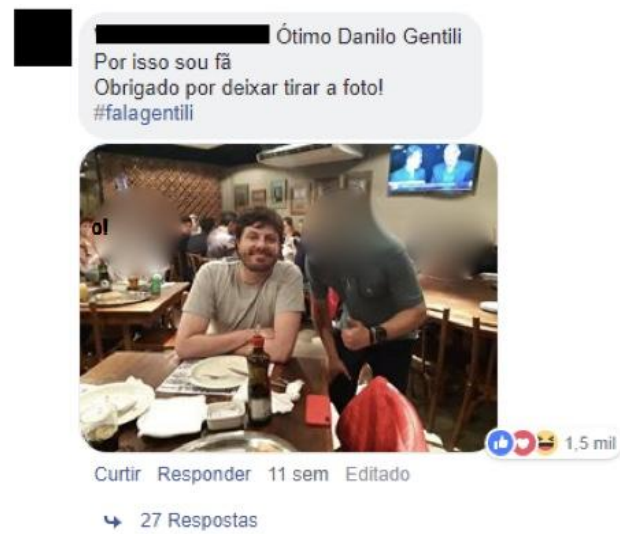

Fonte: Facebook.

No comentário mais relevante, que recebeu sete mil e quinhentas reações, o seguidor propõe uma pesquisa sobre o "número da sorte", que estaria conectado aos números de três candidatos. Com isso, ele recebe seis mil e quinhentas reações de "Amei" representando o número 17, do candidato Jair Bolsonaro, duzentas e trinta e oito reações de "Raiva" (Grr) representando o número 12, do candidato Ciro Gomes, e trinta reações "Triste" representando o número 13, do candidato Fernando Haddad. Não foram colocados outros candidatos na pesquisa informal, com a polarização política aparecendo ainda mais fortemente e pressionando uma escolha entre candidatos específicos. Também aparecem críticas ao comunismo e ao socialismo, nas quais se opõem certas ideias de "liberdade" ao funcionamento do Estados politicamente esquerdistas - explicitamente é citado o nome de Nicolás Maduro e também Cuba é mencionada. Há, portanto, incisivo atravessamento político-partidário entre os comentários dos seguidores da página de Gentili, estimulados pela publicação do humorista - na qual ele não explicitou suas próprias preferências partidárias. Um dos comentários, escrito por uma seguidora que se apresenta como sua "puxa-saca de marca maior", exalta a biografia de Gentili caracterizado-o como questionador, corajoso e provocador. Outro comentário liga a hashtag \#falagentili - resposta à hashtag \#CalaBocaGentili que chegou aos trending topics do Twitter graças a uma manifestação do humorista na qual critica o movimento feminista ${ }^{14}$ - a uma imagem de um fã ao lado do humorista. Assim, podese sugerir que o espaço de interação criado nos comentários serviu como arena de publicização de opiniões supostamente alinhadas àquilo que os seguidores entenderam como sendo a posição políticopartidária de Gentili - muito embora essa posição nunca seja explicitada. O antagonismo aos estereótipos da esquerda política é recorrente nos comentários.

Por outro lado, ao atentarmos para as publicações de Gregório Duvivier no mesmo período, sua posição autodeclarada é de esquerda, apesar de não-partidária. Essa escolha apareceu nas suas escolhas pessoais por candidatos: todos os seus votos foram anunciados em sua página, com explicações. No entanto, a tônica do conteúdo foi de antagonismo às posições de Bolsonaro e de divulgação de estratégias para que ele não vencesse.

14 Disponível em https://emais.estadao.com.br/noticias/gente,danilo-gentili-publica-tuite-polemico-einternautas-reagem-com-a-hashtag-calabocagentili,70002502438, acesso em 03 de abril de 2019. 
A publicação de maior engajamento na página de Gregório Duvivier durante a campanha eleitoral é do dia 29 de setembro de 2018: um vídeo ${ }^{15}$ que reuniu diversas artistas mulheres manifestando o porquê de se aproximarem do movimento \#elenão. Suas declarações foram compartilhadas nas redes sociais das artistas, a partir de desafios e correntes para que todas declarassem razões para não votarem em Jair Bolsonaro. Duvivier compartilhou em sua página uma compilação de vídeos na qual mulheres artistas se posicionavam abertamente contra o candidato. No texto da publicação, Duvivier convocou os seguidores para a manifestação nas ruas, organizada pelo grupo Mulheres contra Bolsonaro simultaneamente em várias cidades do Brasil. O texto era: "É HOJE!!! Chegou o grande dia, o dia de mostrarmos ao mundo inteiro que o Brasil não aceitará calado às ameaças a democracia que Bolsonaro representa. Todas e todos nas ruas, a partir das $15 \mathrm{~h}$, em todo o Brasil. \#EleNão \#EleNunca \#OFilhoDeleTambémNão \#MulheresContraBolsonaro". Com essa publicação, Duvivier assumiu sua posição contrária à candidatura de Jair Bolsonaro. No total, foram quarenta e quatro mil e noventa e sete interações no post.

Figura 4: Os cinco principais comentários da publicação de Gregório Duvivier (durante o período eleitoral).
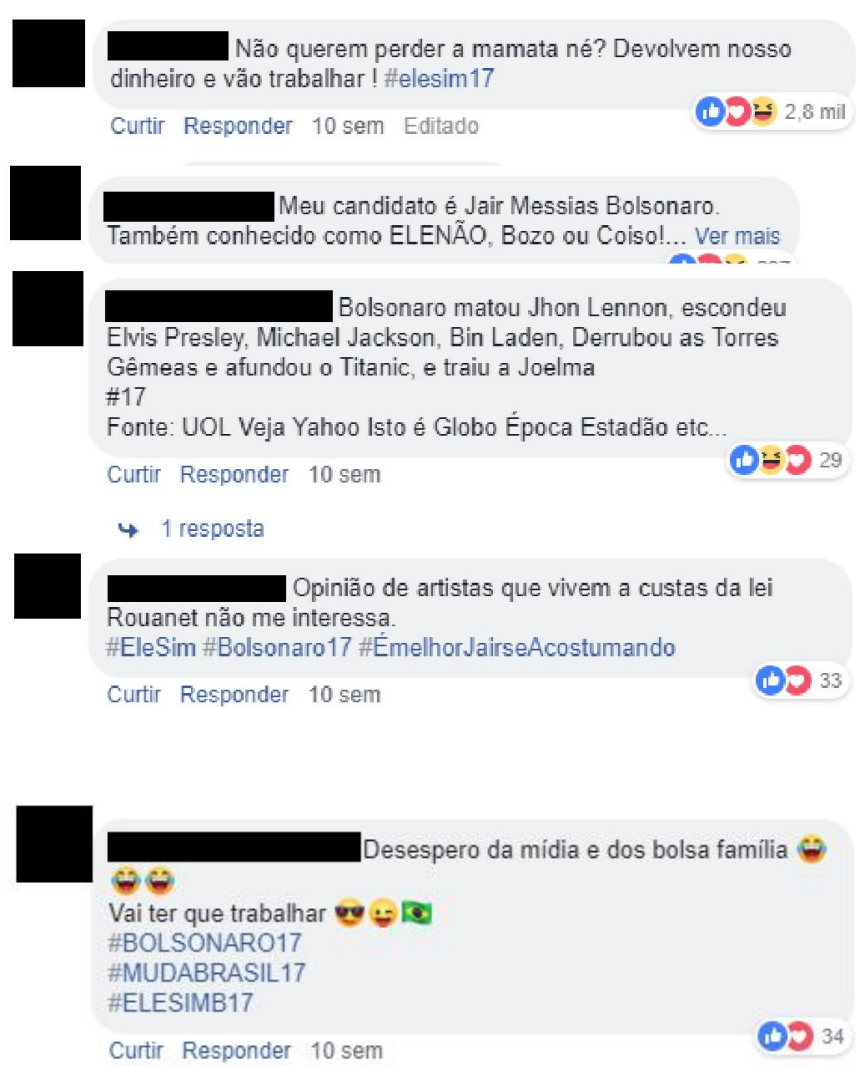

Fonte: Facebook.

Nesta publicação, todos os comentários mais relevantes eram a favor de Bolsonaro e contra a manifestação. Importante destacar alguns argumentos que surgem junto dos comentários para esse posicionamento, como as expressões "vai ter que trabalhar" e "desespero dos bolsa família", ligadas ao

\footnotetext{
${ }^{15}$ Disponível em https://www.facebook.com/gregorioduvivier/videos/279538052661415/.
} 
suposto assistencialismo inócuo de programas sociais propostos pelo Partido dos Trabalhadores ao longo de seus mandatos. Também o funcionamento da Lei Rouanet é usado como crítica ao chamamento da manifestação, sugerindo que "artistas vivem às custas" dos valores arrecadados pela Lei. Há uma ironia quanto à culpabilização de Bolsonaro por eventos desastrosos ocorridos nos últimos anos, bem como a incorporação de expressões pejorativas como "Coiso" e "Bozo" no sentido de afirmar o voto a Bolsonaro. Entre as quatro publicações e comentários aqui analisados, esta é a única que tenta arregimentar seguidores da página para participar de uma manifestação de rua, empregando a rede social Facebook como ferramenta de comunicação para protestos fora da internet.

\section{PEDAGOGIAS DA POLARIZAÇÃO ONLINE}

As duas páginas selecionadas para estas análises fazem parte de uma construção de sociedade atual e trazem marcas da cultura do tempo presente no Brasil: polarizada e maniqueísta (GALLEGO, 2018). É neste cenário que é ainda mais relevante entender quantos significados estão sendo produzidos e questionados na circulação das opiniões nas redes sociais online. Rosa Fischer (1997) já lembrava que o problema da "pedagogização" da mídia deve ser levado em conta porque vivemos em um tempo de

deslocamento de algumas funções básicas, como a política e a pedagógica, que gradativamente deixam seus lugares de origem - os espaços institucionais da escola, da família e dos partidos políticos -, para serem exercidas de um outro modo, através da ação permanente dos meios de comunicação. (p. 61).

Entendemos que este seja um dos efeitos da pedagogização da mídia que, para Fischer (1997), traz consigo diferentes estratégias para formar enquanto informa - nunca de maneira despretensiosa. Os veículos de comunicação em massa sempre exerceram um papel formador ao construir cenários e personagens que determinam padrões, ao definir as notícias que pautam as discussões na sociedade e ao definir quais vozes deverão ocupar o espaço da grade de programação. Em certas proporções, as redes sociais online rompem algumas barreiras de decisão dos grandes veículos e, neste contexto, assumem um papel de chancela, como um selo de garantia de relevância. Ainda, na análise de Fischer, cada produção midiática é vista "como materialidade discursiva, como gerador e veiculador de discursos, como tecnologia de comunicação e informação. E, como tal, na sua condição de constituidor de sujeitos sociais" (1997, p. 61). Esses sujeitos não estão mais dispostos a apenas receberem informações. Nessa lógica, "descobre-se a complexidade não só dos produtos culturais [...], mas do próprio sujeito-receptor (que deixa de ser visto apenas como consumidor, para ser percebido como ator num espaço de produção cultural)" (FISCHER, 1997, p. 61).

Em consonância com Fischer, Freire Filho (2017, p. 74), sugere que "a internet sobressai, na atualidade, como o mais prodigioso arquivo e tribunal de experiências e de manifestações emocionais controversas, proscritas ou legitimadas socialmente". O mesmo autor (p. 68) salienta que "a pedagogia 
das emoções efetuada por instituições como a família, a escola e a mídia sanciona movimentos de aproximação e de afastamento social”. Ele ainda amplia a discussão ao sugerir que

\begin{abstract}
A pedagogia das emoções efetuada por instituições como a família, a escola e a mídia sanciona movimentos de aproximação e de afastamento social, apresentando - desde a infância determinados tipos de indivíduos, experiências e ambientes como sendo, intrinsecamente, amáveis, temíveis, repulsivos ou odiosos, dignos de compaixão ou merecedores de desprezo, fontes de alegria ou de infelicidade. Qualquer desvio significativo no que tange às orientações emocionais pode ser identificado como transtorno que exige vigilância, castigo, psicoterapia ou outra modalidade de tratamento médico. Para aqueles que se alinham às diretrizes afetivas, são anunciadas variadas recompensas no âmbito subjetivo, doméstico, profissional ou celestial. (FREIRE FILHO, 2017, p. 68).
\end{abstract}

Nas publicações das páginas trazidas na seção anterior, e para o período delimitado, temos o exemplo sobre como os seguidores se declaram fãs dos artistas mesmo em assuntos que não estejam ligados somente às suas produções humorísticas, mas também às suas opiniões políticas. Sobretudo nos comentários mais relevantes da publicação de Gregório Duvivier do dia 29 de setembro de 2019 (Figura 4), parece que há algo que desperta a urgência em participar da publicação, de deixar marcada uma insatisfação, por vezes, de forma bastante rigorosa. Nesse sentido, vale destacar que

as plataformas para redes sociais e os sites de compartilhamento de vídeos não fornecem aos usuários a oportunidade de atuar, apenas, como confessandos emocionais ou voyeurs das emoções alheias - permitem que eles se convertam, ainda, em analistas e juízes. Todos os participantes se consideram autorizados a arbitrar a legitimidade da reação emocional de outrem, a patrulhar as fronteiras dos afetos, disciplinando condutas dentro e fora do ciberespaço. [...] Conhecimentos científicos, a psicologia popular, textos sagrados, crenças morais, estereótipos culturais e experiências biográficas são acionados para embasar o julgamento - célere e taxativo - das expressões e das condutas emocionais alheias. (FREIRE FILHO, 2017, p. 75, grifos nossos).

É o "julgamento célere e taxativo" da urgência opinativa que marca uma parte dos comentários publicados por usuários do Facebook nas publicações de Danilo Gentili e Gregório Duvivier - embora, de acordo com o recorte feito para este artigo, pareça mais evidente que a urgência opinativa funcione entre os seguidores do primeiro, e não necessariamente entre os seguidores do segundo. Talvez mais importante do que o engajamento positivo seja o engajamento reativo expresso por meio das reações negativas que ganham proeminência nos atos de curtir, compartilhar e comentar. Não por acaso o Facebook desenvolveu, para além do botão de "curtir", as reações de "amar", "rir" (haha), "enraivecerse" (grr); elas são responsáveis por engajamentos mais específicos, mais matizados dos usuários.

\title{
"A DEMOCRACIA É UMA DELÍCIA": A OPINIÃO NAS REDES SOCIAIS DA INTERNET
}

O título desta seção retoma um comentário de um seguidor de Gregório Duvivier, que mencionou a fala irônica do então candidato Ciro Gomes em um dos debates presidenciais da campanha de 2018 sobre a existência da URSAL (Figura 2). Enquanto figura de linguagem, a ironia do 
comentário se caracteriza precisamente por afirmar o contrário do que está dito: que a democracia não seria uma delícia. Para balizar essa discussão, sublinhamos que uma das publicações (Figura 2) foi um convite aberto para participação em um protesto que, à época, visava afirmar os princípios democráticos marcando antagonismo em relação às posições do então candidato Jair Bolsonaro; sublinhamos, também, que a liberdade foi tema de um dos comentários que mais gerou engajamento de usuários (Figura 3), aparecendo na publicação de Gentili do dia 16 de setembro de 2018, comentário este no qual a seguidora vincula o princípio democrático de liberdade ao capitalismo e a privação (do princípio democrático liberdade) ao comunismo. Assim, propomos uma articulação, mesmo que provisória, entre as disputas dos vários sentidos da democracia para esses usuários das redes sociais da internet por meio do exercício da "urgência opinativa" que vimos tangenciando até aqui.

Se a disputa pelo sentido da democracia acontece em todos os lugares, e se a disputa pela existência passa pelo exercício do direito à voz, todas as relações sociais são, de alguma forma, lutas por identificação, pertencimento e reconhecimento (HONNETH, 2009). Essa disputa não foi apenas transferida para as redes sociais na internet, mas seguiu o fluxo comunicacional do tempo presente (CASTELLS, 2017). Assim, é impossível não remeter o uso das redes sociais na internet ao conceito habermasiano de esfera pública. Tal conceito ajuda a contextualizar aquela disputa, uma vez que considera este um espaço em que atores públicos e privados discutem assuntos públicos - muito embora queiramos realçar aspectos não tão afins à esfera pública de Habermas. A esfera pública contribuiria para a formação de uma opinião pública, com uma visão de consenso. Wilson Gomes e Rousiley Maia (2008, p. 35) ampliam a compreensão de esfera pública, seja segundo o modelo helênico ou burguês, e a explicam como a instância da "vida social em que interesses, vontades e pretensões que comportam consequências concernentes à comunidade política se apresentam na forma de argumentação ou discussão". Nessa direção, há outros autores contemporâneos que indicam uma reconfiguração da democracia deliberativa, apontando para uma refeudalização da esfera pública (MURDOCK, 2018).

Mas como fazer com que essas vontades e pretensões, grandes influenciadoras das razões pessoais, circulem em uma mesma esfera, em harmonia e balizadas pela racionalidade, para tratar de assuntos gerais - ou, como é o caso, polêmicos? O cenário politicamente polarizado do Brasil faz com que a esfera pública se torne produtora de opiniões também polarizadas, de forma que os indivíduos sejam compelidos escolher um (e somente um) dos lados a fim de ocupar o debate e repelir o outro, tido como seu inimigo. É o que acontece com a organização das comunidades de fãs e de antifãs de determinadas posições políticas. Com isso, sugerimos que as interações que analisamos aqui se realizaram de forma tensa e intensa em um cenário de dissenso, marcado pelo antagonismo (MOUFFE, 2003; 2015).

Chantal Mouffe (2003, p. 15) sugere que "A política visa a criação de unidade num contexto de conflito e diversidade; está sempre preocupada com a criação de um 'nós' pela determinação de um 'eles"'. Ainda, sugere a superação da noção de inimigo geralmente vinculada ao "eles" e sua substituição, mais afeita à democracia, pela noção de adversário (MOUFFE, 2015). Na relação com o inimigo, existiria puro antagonismo; mas, para o exercício e convívio democráticos mais produtivos, 
seria o agonismo, isto é, um cenário no qual as relações sociais estejam permanentemente tensionadas por pela diversidade constitutiva dos interesses dos grupos que compõem as sociedades:

Enquanto o antagonismo é uma relação nós/eles em que os dois lados são inimigos e não possuem nenhum ponto em comum, o agnonismo é uma relação nós-eles em que as partes conflitantes, embora reconhecendo que não existe nenhuma solução racional para o conflito, ainda assim reconhecem a legitimidade de seus oponentes. Eles são "adversários", não inimigos. (MOUFFE, 2015, p. 19, grifo nosso).

Os comentários de apoio, que aproximam os seguidores das páginas aos posicionamentos políticos de Gregório Duvivier e Danilo Gentili, são indícios de um senso de comunidade e pertencimento, mas ao mesmo tempo indicam, e de maneira dramática, que ambos os grupos (embora bastante desiguais em números) podem manter entre si relação de antagonismo. Mesmo que não se possa supor que seguidores de um humorista sejam sempre e necessariamente aqueles que criticam o outro, é possível sugerir que suas opiniões expressam as relações de antagonismo amiúde constituintes da polarização política na qual se encontra a sociedade brasileira. Disputam-se os sentidos para o que seria um convívio social apropriado ou o que seria a liberdade propriamente dita, com o agravante de que opiniões discordantes são consideradas inimigas. Assim, as redes sociais na internet potencializam, ao mesmo tempo, o alinhamento de pertencimentos políticos semelhantes, e também intensificam o dissenso antagonístico entre as diferentes opiniões por se constituírem em um espaço compartilhado, em uma esfera de coexistência não necessariamente 'deliberativa'.

As discussões nas redes sociais da internet indicam, muitas vezes, que a organização das interações e a formação de comunidades de fãs obedeçam ao princípio de um individualismo grupal: como o caso da seguidora de Gentili que, em seu comentário, elenca os elementos que ela, individualmente, acredita ser constituintes da liberdade, ganhando mil e oitocentas reações pela sua opinião. Trata-se de uma radicalização do sentido democrático da Grécia Antiga, na qual a democracia foi criada e na qual essa mesma palavra era expressão de um ódio ao povo, à massa (RANCIĖRE, 2014) - sentido este que pode estar presente na ironia que dá título a esta seção. De modo mais assustador, trata-se de um funcionamento democrático baseado no eu individual e não no nós coletivo; trata-se de um funcionamento democrático que faz sucumbir o coletivo plural, diverso, ao se orientar pela tirania de uma opinião singular que, a princípio, parece ser unívoca às opiniões daqueles que curtiram um tal comentário. A perversão democrática contemporânea, que transforma a maioria em regime totalitário, redunda na supressão de seus diversos, reduzidos a inimigos (RANCIĖRE, 2014).

O enfrentamento da vitalidade democrática assumia assim a forma de um double bind [duplo vínculo] simples de resumir: ou a vida democrática significava uma ampla participação popular na discussão dos negócios públicos, e isso era ruim, ou significava uma forma de vida social que direcionava as energias para as satisfações individuais, e isso também era ruim. A boa democracia deveria ser então uma forma de governo e de vida social capaz de controlar o duplo excesso de atividade coletiva ou de retração individual inerente à vida democrática. (RANCIĖRE, 2014, p. 17). 
Em outra direção, para Mouffe (2003, p.11) é um equívoco acreditar que uma "boa sociedade" é aquela sem antagonismos. Pelo contrário, as diferenças são necessárias para a democracia somente quando as diferenças não se traduzem em desigualdades. Pensar em um bem comum, neste cenário, não significa pensar que o que é bom para um indivíduo terá exatamente a mesma representação e valor para os outros, mas implica buscar um estado adequado para o convívio dos grupos e para o governo dos cidadãos ao mesmo tempo em que é garantida a possibilidade de disputa por diferentes sentidos do próprio bem comum. Nesse sentido, garantido o agonismo, garantir-se-ia também a liberdade.

Porém, conforme vimos mostrando, algumas publicações das páginas dos dois humoristas e, principalmente, alguns comentários de seus seguidores buscam sobrepujar a opinião diversa, calandoa, fazendo dos afetos o móbil para a expressão opinativa. Não é apenas a visão simplista de que a democracia é a tirania da maioria a partir da qual se desenvolvem as interações nas páginas analisadas. Há um problema mais preciso, cujos rastros pudemos entrever no material trazido, que diz respeito à anulação da opinião diversa - isto é, ao tratamento conferido ao outro como inimigo que deve ser aniquilado.

\footnotetext{
Para funcionar, a democracia exige que haja um choque entre posições políticas democráticas legítimas. É assim que o confronto entre esquerda e direita deve ser. Esse confronto deve oferecer formas coletivas de identificação suficientemente fortes para mobilizar paixões políticas. $\mathrm{Na}$ ausência dessa configuração adversarial, as paixões não dispõem de uma válvula de escapa democrática e as dinâmicas agonísticas do pluralismo são obstruídas. Corre-se o risco, portanto, de que o confronto democrático seja substituído pelo confronto entre formas essencialistas de identificação ou entre valores morais não negociáveis. (MOUFFE, 2015, p. 29, grifos nossos).
}

É nesse confronto grifado no excerto anterior em que se manifestaram as polarizações nas páginas que vimos mostrando. A lógica (antidemocrática) é a de que, se a opinião de um indivíduo (fã, seguidor, internauta, cidadão) é contrária à de outro, estabelece-se uma disputa bélica cujo objetivo não é, nem de um lado nem de outro, convencer de algo diferente ou dissuadir da importância ou validade de seus argumentos. Para ambos, a opinião expressa de modo diverso é um inimigo a ser exterminado.

\section{CONSIDERAÇÕES FINAIS}

Argumentamos, a partir de publicações e comentários mais relevantes nas páginas do Facebook de Danilo Gentili e Gregório Duvivier entre os dias 26 de julho e 04 de outubro de 2018, que a polarização política na qual o Brasil, como um todo, esteve imerso no período eleitoral pode ser interpretada à luz de alguns conceitos pertinentes para a Educação. Nesse sentido, destacamos as singularidades das redes sociais na internet e as peculiaridades dos atos de curtir, compartilhar e comentar (RECUERO, 2009; 2014), desde a perspectiva do estatuto pedagógico da mídia (FISCHER, 1997 ; 2012) e da pedagogia das emoções (FREIRE FILHO, 2017) operada por meio da internet. Essas são formas de os usuários das redes sociais online aprenderem a se posicionar politicamente na relação que estabelecem com as publicações das fanpages dos dois humoristas. É possível sugerir 
que as comunidades de seguidores dos dois humoristas foram, pelo menos para o período, comunidades de seguidores de suas posições políticas. Se Duvivier manteve-se explícito em relação ao seu pertencimento à esquerda política e ao seu antagonismo a Bolsonaro, Gentili silenciou, em sua página, sobre suas intenções de voto - mas, declaradamente, atacou a imprensa, os jornalistas e uma parcela de professores. Os comentários das publicações tenderam a se alinhar a essas posições, sobretudo entre os seguidores de Gentili, reafirmando também a admiração pela sua figura. A relação ídolo-fã estabelecida e publicizada na forma de comentários e a radicalidade com a qual se estabeleceu o antagonismo entre visões políticas diversas podem ser tais que indicam investimentos e regulações afetivas por meio e graças às redes sociais na internet (FREIRE FILHO, 2017).

Justamente porque o engajamento complexo dos seguidores se deu de acordo com as posições políticas e críticas sociais dos humoristas, pareceu-nos pertinente mencionar abordagens acerca da constituição e funcionamento das sociedades democráticas que atentem para o dissenso como constituidor da democracia (MOUFFE, 2003; 2015), apostando no agonismo como estado de permanente disputa em torno do seu sentido e do seu valor. Em uma versão mais problematizadora do estatuto democrático (RANCIĖRE, 2014), apontamos que alguns elementos sobre os quais certas concepções de democracia se assentam (individualidade, opinião, expressão e liberdade) podem funcionar a serviço da perversão democrática, segundo a qual democracia seria a expressão máxima da maioria numérica. Essas abordagens nos ajudam a pensar que, talvez e em primeiro lugar, o problema que realmente importe para as interações nas redes sociais da internet não é o da impossibilidade de um debate racional que conduz a um consenso, mas o da relação com a opinião diversa enquanto inimigo a ser exterminado. Trata-se de questionar certo individualismo libertário, supostamente afirmado como categoria democrática, que entende a interação não como diálogo, mas como um monólogo impositivo cujo objetivo último é calar (e aniquilar) o interlocutor.

Para finalizar, dados os argumentos arregimentados neste artigo, explicitamos a "urgência opinativa" como a disputa pela imposição de uma determinada perspectiva sobre outra. Ainda que possa concordar com outras opiniões outrora expressadas sobre um tema, a divulgação de uma "opinião urgente" pretende superar tudo o que já foi dito anteriormente, não acrescentando informação nova a qualquer discussão e apenas se impondo pela sua rapidez e indisponibilidade para possíveis diálogos. Nesse processo, os indivíduos engajados na "urgência opinativa" publicam e sustentam as visões que defendem não por meio da exposição racional de argumentos, mas com o fim de anular as opiniões diferentes das suas. A "urgência opinativa" refere-se menos sobre o que dizer, e mais sobre a forma rígida, célere e taxativa de publicização de uma opinião. Assim, são características da "urgência opinativa" a instantaneidade de sua publicação e tendência ao fechamento da discussão. Salientamos que tal "urgência opinativa" opera, sobretudo, por meio de um processo pedagógico exposto nas interações das redes sociais online e orientado por uma forte regulação dos afetos.

\section{REFERÊNCIAS}


1. ARAÚJO, William Fernandes. A construção da norma algorítmica: análise dos textos sobre o Feed de Notícias do Facebook. E-compós, Brasília, vol. 21, n. 1, s/p, jan-abr 2018. Disponível em: https://www.e-compos.org.br/e-compos/article/view/1402 . Acesso em 12 de setembro de 2019.

2. CASTELLS, Manuel. Redes de indignação e esperança: movimentos sociais na era da internet. Rio de Janeiro: Zahar. 2017.

3. D'ANDRÉA, Carlos Frederico de Brito. Controvérsias midiatizadas no Twitter durante transmissões televisivas ao vivo: a rede "exoesqueleto" na abertura da Copa 2014. Revista Famecos, Porto Alegre, v. 23, n.2, $\mathrm{s} / \mathrm{p}, \mathrm{maio}-\mathrm{ago} .2016 .2$ Disponível em: http://revistaseletronicas.pucrs.br/ojs/index.php/revistafamecos/article/view/21106/14166 . Acesso em 12 de setembro de 2019.

4. D'ANDRÉA, Carlos Frederico de Brito. Cartografando controvérsias com as plataformas digitais: apontamentos teórico-metodológicos. Galaxia (São Paulo, online), n. 38, mai-ago., 2018, pp. 28-39. Disponível em: http://www.scielo.br/pdf/gal/n38/1519-311X-gal-38-0028.pdf . Acesso em 12 de setembro de 2019.

5. FISCHER, Rosa Maria Bueno. O estatuto pedagógico da mídia: questões de análise. Educação e Realidade, Porto Alegre, v. 22, n. 2, p.59-79, jul. 1997. Semestral. Disponível em: http://www.seer.ufrgs.br/educacaoerealidade/article/view/71363. Acesso em: 12 set. 2019.

6. FISCHER, Rosa Maria Bueno. Trabalhar com Foucault: arqueologia de uma paixão. Belo Horizonte: Autêntica. 2012.

7. FREIRE FILHO, João. Correntes da felicidade: emoções, gênero e poder. MATRIZes, v. 11, n. 1, abr. 2017, pp. 61-81. Disponível em: https://www.redalyc.org/pdf/1430/143050607005.pdf . Acesso em 12 de setembro de 2019.

8. GALLEGO, Esther Solano (Org.). O ódio como política - a reinvenção das direitas no Brasil. São Paulo: Boitempo, 2018.

9. GOMES, Wilson; MAIA, Rousiley C. M. Comunicação e Democracia: Problemas \& Perspectiva. São Paulo: Paulus, 2008. comunicação. Revista Famecos, Porto Alegre, vol. 25, n. 3, s/p, set/out/nov, 2018. Disponível em: http://revistaseletronicas.pucrs.br/ojs/index.php/revistafamecos/article/view/29387. Acesso em 12 de setembro de 2019. 
HONNETH, Axel. Luta por reconhecimento - a gramática moral dos conflitos sociais. São Paulo: Editora 34. 2009.

MOUFFE, Chantal. Democracia, cidadania e a questão do pluralismo. Política \& Sociedade: revista de sociologia política, Florianópolis, n. 3, out. 2003, pp. 11-26. Disponível em: https://periodicos.ufsc.br/index.php/politica/article/viewFile/2015/1763. Acesso em 12 de setembro de 2019.

MOUFFE, Chantal. Sobre o político. São Paulo: WMF Martins Fontes, 2015.

MURDOCK, Graham. Refeudalização revisitada: a destruição da democracia deliberativa. MATRIZes, São Paulo, vol. 12, n. 2, mai/ago, 2018, pp. 13-31. Disponível em: http://www.revistas.usp.br/matrizes/article/view/149601/147033. Acesso em 12 de setembro de 2019.

RANCIĖRE, Jacques. O ódio à democracia. São Paulo: Boitempo, 2014.

RECUERO, Raquel. Redes Sociais na Internet. Porto Alegre: Editora Sulina, 2009.

RECUERO, Raquel. Curtir, compartilhar, comentar: trabalho de face, conversação e redes sociais no Facebook. Verso e Reverso, vol. 28, no. 68, mai/ago 2014, pp. 114-124. Disponível em: http://www.revistas.unisinos.br/index.php/versoereverso/article/viewFile/7323/4187 . Acesso em 12 de setembro de 2019.

SANTOS, Aloha Boeck Arruda. Pedagogias da polarização política: urgência opinativa nas fanpages de Danilo Gentili e Gregório Duvivier. 2019. 154f. Dissertação (Mestrado em Educação) - Universidade Luterana do Brasil, Canoas.

\section{Luiz Felipe Zago}

Professor Permanente do Programa de Pós-Graduação em Educação, na Linha de Pesquisa Pedagogias e Políticas da Diferença, e Professor do Curso de Comunicação Social - Jornalismo da Universidade Luterana do Brasil (Campus Canoas). Membro do Comitê de Ética em Pesquisa em Seres Humanos da mesma instituição. Editor-gerente da Revista Textura. Graduado em Comunicação Social pela Faculdade de Biblioteconomia e Comunicação da Universidade Federal do Rio Grande do Sul (2006), Mestre (2009) e Doutor (2013) em Educação pelo Programa de Pós-Graduação da Faculdade de Educação da UFRGS na Linha de Pesquisa em Educação, Sexualidade e Relações de Gênero. Já atuou como jornalista e assessor de comunicação. Foi coordenador e consultor de projetos de prevenção às infecções sexualmente transmissíveis, HIV/Aids entre homens que fazem sexo com homens das cidades de Porto Alegre e região metropolitana, tendo sido militante no movimento LGBT (lésbicas, gays, bissexuais, travestis, transexuais e transgêneros) durante 7 anos. Atuou como 
consultor técnico na Coordenação Geral de Saúde Mental, Álcool e Outras Drogas do Ministério da Saúde da Brasil. Suas áreas de interesse são relações de gênero, corpo, sexualidade, Direitos Humanos, produção de subjetividades, mídia radical alternativa, produção social do ódio/violência e ética.

\section{Aloha Boeck Arruda dos Santos}

Jornalista, Mestre em Educação.

\section{Como citar este documento:}

ZAGO, Luiz Felipe; SANTOS, Aloha Boeck Arruda dos. Pedagogias da Polarização no Facebook: redes sociais online e urgência opinativa. Reflexão e Ação, Santa Cruz do Sul, v. 28, n. 3, p. 133-150, ago. 2020. ISSN 1982-9949. Disponível em: <https://online.unisc.br/seer/index.php/reflex/article/view/14165>. Acesso em doi:https://doi.org/10.17058/rea.v28i3.14165. 